\title{
A FAMÍLIA EM SITUAÇÕES DISRUPTIVAS PROVOCADAS POR HOSPITALIZAÇÃO
}

\author{
THE FAMILY IN DISRUPTIVE SITUATIONS CAUSED BY \\ HOSPITALIZATION
}

Arlete C Bomfim*

Ana Cecília Bastos ${ }^{* *}$

Ana M A Carvalho

Bomfim AC, Bastos AC, Carvalho AMA. A família em situações disruptivas provocadas por hospitalização. Rev Bras Crescimento Desenvol Hum 2007(1):84-94.

Resumo: Este trabalho focaliza a situação disruptiva provocada pela hospitalização de um familiar, vítima de doença ou acidente súbitos, requerendo uma reação de enfrentamento por parte da família. São apresentados resultados relativos a seis famílias que viveram essa situação, obtidos por meio de entrevista em profundidade com um dos familiares. Inicialmente, as famílias e as situações são caracterizadas, e são descritas as estratégias de enfrentamento identificadas em cada caso. A seguir, aprofunda-se a análise das estratégias recorrendo a semelhanças e diferenças entre os casos. Em todos os casos ocorre uma reorganização da família em resposta ao evento e às demandas decorrentes; estratégias de enfrentamento variaram, sendo a mais presente o suporte social. Sugerem-se algumas questões para estudos futuros e para a preparação de profissionais da saúde.

Palavras-chave: Família e crise. Estratégias de enfrentamento. Doença e família.

O foco dos estudos e a conseqüente ação social sobre a família são muito recentes, tendo sido privilegiada, por longo tempo, uma mentalidade individualista na defesa dos direitos da criança, do adolescente, da mulher ou do idoso, em um olhar parcial sobre a realidade familiar. Estudos mostram que diversos problemas sociais envolvendo crianças e adolescentes têm uma forte relação com o bem-estar das suas famílias, sem subestimar a influência de outros fatores sociais ${ }^{1}$. $\mathrm{O}$ fato de pertencer, de fazer parte de um grupo, assumindo as características deste grupo como se suas fossem, tem grande importância para o desenvolvimento do indivíduo. Sendo a família um "espaço de convivência humana ao qual cada membro pertence" (p. 85), torna-se um local privilegiado e decisivo para esse desenvolvimento e para a formação de vínculos sólidos e duradouros.

$\mathrm{Na}$ atualidade, a sociedade passa por mudanças altamente velozes e a família tem um papel crucial na adequação do individuo aos novos estilos de vida que continuamente surgem. Donati ${ }^{2}$ descreve a família como sendo um elemento que faz nascer a sociedade, pois o indivíduo não está isolado, mas inserido e pertencendo a um grupo familiar. Reafirma ainda a importância da família para o indivíduo e para a sociedade: "uma sociedade não pode existir se não dispõe de uma cultura que possa pensar e viver de modo 'familiar' aquilo que está além do seu horizonte (aquilo que é desconhecido, estranho, não familiar)" (p. 8). Assim, a capacidade de mudança de uma

Universidade Católica do Salvador, Bahia, Brasil.

** Psicóloga Universidade Federal da Bahia. ApoioCNPq

*** Psicóloga, UCSal/ Universidade Católica do Salvador, Bahia e Universidade de São Paulo. Apoio CNPq/ FAPESP amacarva@uol.com.br 
sociedade consiste em tornar o não-familiar em familiar.

A exposição da família às constantes mudanças impostas pela sociedade contemporânea tem sido objeto de estudo por parte de diversos pesquisadores, que tentam adequar modos de avaliação que facilitem o entendimento das reações familiares. As transições que ocorrem na família ${ }^{3}$ podem ser de caráter normativo, como são considerados os eventos de certa forma previsíveis definidos nos estudos sobre o ciclo de vida $^{4}$, ou não normativos, onde são considerados os eventos ocorridos de forma não previsível, acarretando mudanças imprevistas na dinâmica familiar.

No presente estudo, o interesse se concentra sobre o adoecimento de início agudo, súbito e inesperado, em indivíduos previamente hígidos, configurando uma crise na família. O início agudo exige da família uma mobilização rápida para adaptar-se a este momento de transição e capacidade de lidar com a crise desencadeada. As famílias mais abertas no relacionamento entre seus membros, mais flexíveis e com uma rede de apoio consistente, presumivelmente terão mais facilidade no manejo da situação.

Estes momentos de mudanças não normativas, que desencadeiam invariavelmente outras mudanças, não podem ser considerados apenas como negativos: “...nas situações 'dolorosas', em que por algum tempo se vive sob o domínio da dor, do sofrimento, em alguns momentos percebidos como sem saída, como só a morte se configuraria como tal, podem ocorrer reviravoltas, transformações - e da morte emerge uma nova vida com mais vigor." 5

A abordagem proposta aqui refere-se ao internamento de paciente agudo em UTI. Partindo-se da hipótese de que o ambiente da UTI tem características potencialmente estressantes e de que o internamento de um familiar na UTI pode ser uma fonte de estresse para toda a família, e na tentativa de entender a situação vivenciada pela família exposta a um internamento hospitalar, foi feito um estudo com seis famílias que tinham pacientes seus internados em uma UTI para adultos por causa aguda, ou seja, um evento de caráter súbito e inesperado.
Entende-se, aqui, conforme sugerido na abordagem Bioecológica do Desenvolvimento Humano de Bronfenbrenner ${ }^{6}$, que o microssistema familiar, com todas as suas particularidades e complexidades, é obrigado, por força dessas circunstâncias, a se relacionar com um novo microssistema que é a UTI. Estes são caracterizados como dois ambientes, até então totalmente diversos, que necessitam tornar-se familiares, formando um mesossistema, para que a convivência seja minimamente harmônica e atinja o objetivo desejado para as famílias e para a UTI, que seria o cuidado efetivo a ser prestado ao familiar-paciente.

A pesquisa foi estruturada com base no modelo PPCT (Processo- Pessoa- ContextoTempo $)^{7}$. Parte-se do pressuposto de que, para entender a percepção que o familiar tem do momento vivido e do seu enfrentamento da situação (Processo), seria necessário considerar as características individuais da família envolvida, suas crenças, atividades, metas e motivações (Pessoa), entender os dois ambientes em questão e todo o contexto em que eles estão inseridos (Contexto) e, por fim, as questões referentes à história e eventos nodais vivenciados por estas famílias (Tempo).

Recorremos também, como referencial teórico, ao conceito de coping. O coping (modo ou estilo de enfrentamento) é concebido como um conjunto de estratégias que o individuo usa para se adaptar a situações geradoras de estresse. Inicialmente foi concebido como um mecanismo de defesa, que o indivíduo utiliza conscientemente como forma de lidar com situações conflitantes. Esta visão ${ }^{8}$, classificada como inflexível e inadequada com relação à realidade externa, evoluiu até chegar aos estudos do grupo de Lazarus e Folkman na década de $80\left(\operatorname{apud}^{9}\right)$, que passaram a conceitualizar o coping como um processo transacional entre a pessoa e o ambiente, enfatizando o processo em si.

\section{MÉTODO}

Os participantes do estudo são familiares de pacientes internados em UTI geral para adultos. Foram inicialmente selecionados 15 pacientes que sofreram internamento inesperado provocado por acidente ou doença aguda, com 
permanência, na UTI, de no mínimo cinco dias; destes, apenas sete tiveram uma família disponível para participar da pesquisa. As entrevistas foram feitas com o paciente ainda internado na UTI, com exceção de uma, que foi realizada imediatamente após a alta para outra unidade.

Os familiares pesquisados tinham convivência com o paciente antes do internamento e acompanharam todo o processo, desde a entrada no hospital até o momento da entrevista. Havendo mais de um familiar que preenchesse os critérios para participar da pesquisa, a escolha foi feita pelo próprio grupo familiar. Em um caso, a entrevista foi feita com duas pessoas. Foi utilizado o termo familiar-paciente ${ }^{10}$ para designar o paciente internado, facilitando sua diferenciação dentro do grupo familiar.

Foi elaborado um roteiro para entrevista semi-estruturada, avaliado e reestruturado através de um estudo piloto. O roteiro explorava a estrutura da família, natureza das relações entre seus membros, e a seguir investigava o evento desencadeador da crise e suas repercussões na família. A coleta foi realizada pela primeira autora, enfermeira na unidade em questão. Tanto no estudo piloto como no definitivo, o início do trabalho só se deu após a assinatura do impresso de consentimento informado por parte de cada participante, com a garantia de salvaguarda do anonimato do paciente e do seu familiar. O projeto foi submetido e aprovado pelo comitê de ética do hospital.

$\mathrm{O}$ instrumento foi aplicado em uma pequena sala, cedida pelo hospital. As entrevistas foram gravadas e transcritas, sendo exaustivamente revisadas pelas duas primeiras autoras, em no máximo cinco dias após a sua realização. Foi utilizado ainda um diário de campo, elaborado ao término de cada entrevista. Uma das sete entrevistas foi descartada por problemas de gravação.

\section{RESULTADOS}

\section{Apresentação das famílias}

Na apresentação das famílias são utilizadas imagens de flores, por se tratar de imagens que trazem à lembrança os grupos avaliados, em suas dores e em suas belezas, uns mais vistosos, outros mais acanhados, porém todos merecedores de um lugar ao sol: a Begônia, planta caracterizada por poucas e pequenas flores, porém vistosas e consistentes, lembra a família que ganha o seu nome no sentido de um grupo nuclear, porém firme devido à força da mãe e à consistente rede de amigos; o Antúrio é uma planta que produz flores vistosas, sustentadas por um pequeno eixo, lembrando a família que, apesar das grandes adversidades, é mantida devido à persistência do pai; a Murta é um arbusto que oferece flores discretas, não chama muita atenção pela beleza, mas por seu odor agradável. Nesta família encontra-se uma aparente desagregação, onde apenas a presença do pai é capaz de oferecer um novo perfume à convivência familiar; o Cravo é uma pequena flor de odor inebriante e beleza mediana, porém chama atenção por suas cores; caracteriza a família de um homem forte, que consegue manter a sua vida em uma convivência independente e ao mesmo tempo harmônica com a família; a Hortênsia é caracterizada por cachos com muitas florezinhas e esta família se reconhece justamente pela união entre seus membros, que constitui a sua força; o Girassol é uma flor de cor intensa e rara beleza, tem uma postura ereta, porém solitária, mesmo em meio a uma plantação. Caracteriza esta família a luta solitária no enfrentamento, apesar de seus membros estarem aparentemente juntos.

Para cada família foi elaborado um genograma sintético ${ }^{11}$ para explicitar a estrutura familiar, recurso que se mostrou relevante para identificar a ocorrência e significados atribuídos a episódios de adoecimento na história da família, além de permitir identificar pontos de conflito ou alianças na configuração familiar atual.

\section{A FAMÍLIA BEGÔNIA}

\section{Estrutura da família}

A família Begônia tem como cabeça Bete, professora aposentada, mãe e esposa, mulher de muita fé, que sempre resolveu os problemas da casa e dos filhos sozinha, visto que seu marido sempre viajou muito a trabalho. Bia, a familiarpaciente, é a filha mais velha e a mais ligada à 
mãe; o noivo de Bia, Bruno, está muito presente na família. A segunda filha de Bete, Bartira, mora em outro país, o filho caçula ainda mora na casa dos pais. Há também uma jovem, Bela, criada por Bete como se fosse filha, e Bianca, que viveu com ela desde os oito anos de idade e já mora só.

\section{Características da situação}

$\mathrm{O}$ acidente que vitimou Bia aconteceu na viagem de retorno à sua cidade de origem, após uma semana de trabalho. Com um quadro extremamente grave, deu entrada na emergência do hospital com lesão abdominal e hemorragia interna intensa. Foi encaminhada ao centro cirúrgico e submetida a uma cirurgia de alto risco, sem muitas chances de sobrevivência. Esta foi apenas a primeira intervenção cirúrgica a que ela viria a ser submetida.

A história do internamento de Bia é marcante para todos que a vivenciaram. Quando nada mais havia a ser feito pela medicina, e todos haviam desistido de tentar reverter o quadro, a família foi chamada para tomar ciência da situação. Porém, justamente neste momento, Bia começou a apresentar sinais de melhora, evoluindo de um quadro aparentemente sem retorno para uma reversão súbita e a princípio inexplicável, considerada por Bete e sua família como um milagre.

\section{O processo de enfrentamento}

$\mathrm{O}$ risco de morte que corria Bia era real e deixou toda a família desorientada, como relata Bete: "Me desorientei naquele momento e ficamos aquele resto de dia naquele desespero, que é uma coisa assustadora pra quem está vivendo... Os médicos só diziam: 'O caso dela é grave.' A gente saía daqui, irmão, pai, esse namorado, todo mundo em desespero. Meu Deus, foi angustiante demais.". Os fatos repercutiram na saúde de Bete: “... a gente sente que as carnes tremem, dá pontada na cabeça, a gente... é tanta coisa, que não tem explicação". Bete relatou a sua primeira reação: "Eu tive... o primeiro impacto mesmo, foi de que ela estava morta. Procuraram me confortar, lá em casa, mas a minha cabeça não, ela já tava morta. Vocês estão me enganando!" Depois, diante da certeza da impotência frente ao fato, ela “...só entregava ... Eu entrego, eu entrego meus filhos, meus problemas, eu entrego a Deus pra que Ele faça o que for de melhor, porque a gente não sabe de nada". Bete teve, assim, na fé e na oração a sua arma mais forte para enfrentar a situação vivida.

A família contou também com a ajuda de uma vasta rede de apoio composta por amigos, vizinhos e parentes no enfrentamento da crise. Bianca veio do interior para dedicar-se em tempo integral à situação; a vizinha que Bete define como "fiel", Belmira, também esteve presente nos momentos mais difíceis, segurando literalmente a mão dela; além da corrente de oração, que se espalhou por todos os lugares onde havia alguém conhecido.

Antes mesmo que Bia tivesse alta da UTI Bete, na certeza da sua cura, começou a distribuir para todos os membros da equipe uma mensagem que termina com a seguinte frase: "Ser feliz é poder fazer os outros felizes. Bia agradece a todos que contribuíram com a sua força divina para que ela permanecesse junto de nós!", mostrando assim o que caracteriza o seu enfrentamento da situação, ou seja, um grande otimismo que não se deixa subjugar pela situação extremamente difícil.

\section{A FAMÍLIA ANTÚRIO}

\section{Características da família}

Na família Antúrio, a principal figura é o pai, Artur, o entrevistado; aposentado, viúvo há sete anos, conduz a casa desde a morte da esposa, ocupando-se inclusive dos afazeres domésticos. Antônio, o familiar-paciente, é o filho caçula de Artur. Bastante mimado por todos, é recémformado e arranjou um trabalho apenas um mês antes do acidente. Na casa de cima, construída por Artur, mora Arlene, a filha mais velha, casada com Aurélio, que está desempregado. Os outros filhos são Arnaldo, que saiu de casa por desavença com o cunhado e a irmã, e foi quem mais se empenhou na resolução dos problemas quanto ao internamento de Antônio; Ana, que trabalha e ajuda um pouco no sustento da casa, tem um filho 
de cinco anos; e há ainda mais dois filhos, pouco citados pelo pai, que são casados, Amilton e André.

\section{Características da situação}

$\mathrm{O}$ acidente se deu por uma "brincadeira" de um colega que empurrou Antônio, levando-o a cair e bater a cabeça. Este colega, intensamente consternado, está sendo consolado por Artur, que não o acusa pelo ocorrido. Antônio, após voltar à consciência, tem-se portado de forma distante com a família, ficando calado na maior parte do tempo, não estando claro se isso é relacionado ao seu estado emocional, ou ao próprio quadro da doença.

\section{O processo de enfrentamento}

Os primeiros momentos, logo após o acidente, foram difíceis, devido à inabilidade do pessoal do hospital do interior para prestar os primeiros socorros; porém, imediatamente, toda a família foi acionada, estando, em instantes, todos presentes para que as providências fossem tomadas, sempre sob o comando de Artur. Contam ainda com uma rede de apoio entre a família extensa e amigos. O episódio do acidente de Antônio tem servido para iniciar uma reaproximação do irmão que estava afastado, sendo este o que está mais presente, depois do pai, na assistência a Antonio. Artur ainda se preocupa com a vida dos outros filhos, cuidando para que a rotina de trabalho e estudo dos outros não seja muito alterada.

\section{A FAMÍLIA MURTA}

\section{Características da família}

A família Murta é composta por Marcos (familiar-paciente), único homem entre irmãs (Marta, Marilda e Márcia), com uma mãe (Maria) já idosa, porém ainda lúcida; não há referências ao pai. Marilda tem um filho (Mauro), que teve um importante papel no momento do internamento. Márcia, a entrevistada, secretária executiva, é a irmã que está sempre pronta para ajudar os membros da família, dedicando-se com afinco nos momentos de crise. Marcos é casado com Madalena e tem três filhos: Mateus de 12 anos,
Mila de 21 anos e Marina de 22 anos. Marcos, aposentado, assume o papel de cuidador na família, uma vez que Madalena trabalha o dia todo e estuda à noite. Madalena foi a pessoa convidada para participar da entrevista, porém, na hora pediu para Márcia ir no seu lugar.

\section{Características da situação}

O internamento de Marcos ocorreu em um clima de confusão e desentendimentos, marcado por um descaso inicial da família nuclear, que minimizou de forma irresponsável a gravidade do quadro, abstendo-se de agir nos primeiros momentos da doença. Só após algum tempo é que tomaram consciência da verdadeira situação e começaram a se culpar pelo ocorrido.

\section{O processo de enfrentamento}

Os filhos, atordoados, alheios à verdadeira situação do pai, não souberam como agir e esperaram a chegada da mãe para que esta tomasse as decisões. Ao tomar consciência da gravidade do quadro de Marcos, o que não aconteceu de imediato, mas só depois que a equipe médica explicou do que se tratava, Madalena passou a culpar a filha mais velha (Marina) por não ter tomado uma providência de imediato, isentandose de qualquer responsabilidade

Com uma rede de apoio quase que inexistente, Madalena teve que recorrer à família de origem de Marcos, com quem não mantinha qualquer relação há anos, e a quem entrega a responsabilidade de cuidar do marido, visto que ela tinha que cuidar do seu trabalho. Quem conduziu toda a situação foi Márcia, apoiada pelas outras irmãs que, tendo uma rede de apoio mais consistente, conseguiram levar, de uma forma mais amena, uma circunstância que tinha tudo para ser trágica. Tiveram a importante ajuda de Mauro, filho de Marilda, que acompanhou Márcia até a casa de Marcos, levando-os para a emergência do hospital. Outra presença importante é a de Marta, a irmã mais velha de Marcos, que sempre está presente no hospital, ajudando Márcia a enfrentar a situação.

Após o momento inicial, a família, cons- 
cientizada da gravidade do problema, começou a ter outras reações. Marina, culpabilizada pela mãe, começou a apresentar hipertensão relacionada ao estresse gerado pela situação. Mila inicialmente se afastou, porém, no momento da coleta de dados, havia começado a se reaproximar para ajudar, disponibilizando-se inclusive a dormir com o pai após a alta da UTI.

\section{A FAMÍLIA CRAVO}

\section{Características da família}

A família Cravo é composta por Carlos, o familiar-paciente, 80 anos, filho único, pai, avô e bisavô, descrito como homem independente, viúvo há nove anos, morando sozinho em uma fazenda no interior, com a assistência dos filhos que moram perto. Carlos tem seis filhos, três mulheres: Carolina, Célia (as entrevistadas) e Cristina; e três homens: Cornélio, Clóvis e César, além de uma filha de cinco anos (Cíntia), que foi citada com certo constrangimento por Carolina e Célia. Carolina, a primeira entrevistada, tem 52 anos, é autônoma e é a única que mora em outra cidade. A segunda, Célia, 50 anos, é professora e mora na mesma região que o pai.

\section{Características da situação}

O internamento de Carlos deu-se em decorrência de um grave acidente automobilístico. Vindo do interior para atendimento mais especializado, encontrava-se na UTI em estado grave, devido principalmente a um TCE (Trauma Crânio Encefálico). Carolina, presente todo o tempo, conversa com o pai insistentemente, mesmo sabendo que não terá uma resposta aparente.

\section{O processo de enfrentamento}

A reorganização estrutural da família deuse de forma natural e circunstancial: os filhos que se encontram no interior ficaram de dar continuidade e cuidar das coisas do pai na sua ausência e a filha que se encontra na capital (Carolina), também naturalmente assumiu a posição de cuidadora do pai. No final da entrevista, Carolina, não agüentando mais o confronto com a realidade da patologia do pai, principalmente da possibilidade de ele vir a falecer, chorou copiosamente, gerando uma pequena interrupção na entrevista, que passou a ser respondida por Célia. Esta diz entender perfeitamente os sentimentos da irmã, que encontra-se submetida a grande estresse, demonstrando, assim, reconhecimento e gratidão à irmã. Contam com a ajuda de duas pessoas no hospital, um médico e um farmacêutico, além de outros médicos, amigos da família, que trabalham no hospital e têm informação mais direta do caso. Referem como de grande valor, também, a ajuda recebida de outros familiares que se encontram em situação semelhante.

\section{A FAMÍLIA HORTÊNSIA}

\section{Características da família}

A família Hortênsia é composta por seis filhos adultos (Heloísa, Helenaide, Hélio, Helení, Hanna, e Helga), todos com família formada, com filhos, totalizando doze netos. Uma das filhas, Heloísa, não se casou e vive agregada a Helenaide, sendo as que ficaram mais próximas durante o internamento. A neta mais velha, Helena (filha de Helení), que foi a entrevistada, também esteve presente desde o primeiro momento, tem trinta anos, é dentista e casada. A maior parte deles mora em uma cidade do interior, onde vive também Hortênsia, o familiarpaciente. Esta é viúva, descrita como uma pessoa presente em todos os segmentos da família, tem dois irmãos que moram na capital, porém mantém relacionamento estreito apenas com Helen, que também acompanhou o internamento e vive em uma casa cedida por ela.

\section{Características da situação}

Foi a característica de procurar estar presente em todos os momentos que levou ao acidente que gerou o internamento de Hortênsia. Toda a família mora em uma cidade próxima da Capital; como uma das filhas (Helenaide) começou a fazer viagens freqüentes, Hortênsia achou importante 
a sua presença neste momento e, em uma destas viagens, deu-se um grave acidente, estando no carro o motorista, Hortênsia e Helenaide, que também ficou seriamente ferida. Os primeiros socorros foram prestados no local do acidente, sendo então levados para o hospital e acionada a família. As duas, mãe e filha, deram entrada na UTI, sendo que Helenaide permaneceu por apenas dois dias até a alta; Hortênsia, porém, apenas iniciava a sua longa caminhada devido a sérias fraturas, agravadas pelo fator da idade avançada. No momento da entrevista, já com 58 dias de internamento, com discretos sinais de melhora, foi encontrada uma família exausta, porém muito esperançosa na possibilidade de recuperação. Com o passar do tempo, o estado de saúde de Hortênsia foi se complicando cada vez mais. Exposta a grandes sofrimentos e dores, apesar dos analgésicos e sedativos, havia momentos em que era necessário que ficasse acordada para colaborar com o tratamento, o que se tornou uma grande fonte de estresse para a família, que se sentia impotente diante da situação. Um dos pontos mais difíceis para a família foi que, além de presenciar toda a trajetória de sofrimento, ocorria a instabilidade do quadro clínico, que mudava com muita freqüência, trazendo esperança e logo depois desilusão.

\section{O processo de enfrentamento}

Hortênsia, católica, participava ativamente das atividades religiosas da sua cidade, tendo sido a fé uma forma marcante de enfrentamento durante o período de internamento. No quarto da UTI foram dispostos vários objetos que lembravam e mantinham esta fé da família, como terço, estátuas de santos, fotos da paciente em oração. Não havendo alguém em especial que sempre estivesse à frente, este papel era exercido por todos de forma alternada, a depender da condição físico-emocional de cada um no momento. Muitas vezes houve instantes de desespero e de pouca saúde física, mas sempre havia uma pessoa que agia contribuindo para manter o equilíbrio familiar. A família constituiu-se assim numa rede de apoio sólida e consistente no enfrentamento da situação.

\section{A FAMÍLIA GIRASSOL}

\section{Características da família}

A família Girassol é pequena: Gilda, mãe e avó, Gaspar, filho que mora em uma cidade distante e Gabriela, filha mais velha e principal provedora da casa, mãe de Guto. Gabriela, a entrevistada, é professora, trabalha os três turnos para manter uma renda adequada às necessidades da família. Gilda, familiar-paciente, é descrita pela filha como uma pessoa forte e controladora, que acompanha a vida dos filhos e neto de perto, preocupando-se em demasia com os mínimos detalhes; o filho, Gaspar, apesar de morar distante, tem que telefonar para a mãe com frequiência para tranqüilizá-la. Guto foi, na verdade, educado por Gilda, visto que Gabriela sempre trabalhou fora. O relacionamento de mãe e filha (Gilda/Gabriela) é marcado por uma grande dependência. Morando juntas desde a separação de Gilda, dividem tudo, das despesas até as tomadas de decisão. Guto, em plena adolescência, mantém relacionamentos bastante conflituosos com as pessoas da família, principalmente com Gilda que, segundo Gabriela, não entende os jovens de hoje.

\section{Características da situação}

Vítima de uma patologia aguda de extrema gravidade, Gilda foi submetida a várias cirurgias, tendo evoluído para um quadro de infecção generalizada e insuficiência de múltiplos órgãos. A família sempre foi orientada pela equipe médica quanto aos grandes riscos que a sua mãe corria. A internação na UTI foi avaliada pela família como um momento muito difícil, onde o cansaço era extremo. Com o passar dos dias, foram se avolumando as fontes de estresse: além da ausência da pessoa amada, é relatada a instabilidade do quadro, onde um dia nunca é igual ao outro; a situação foge ao controle, criando o sentimento de impotência.

\section{O processo de enfrentamento}

A família é caracterizada pelo isolamento; mesmo nos momentos de crise preferem resolver os problemas entre eles. Gilda, apesar de vir de 
uma família extensa, composta por dez irmãos, não mantém relacionamento com eles, exceto por uma irmã (a caçula - Gina). Este afastamento dos familiares da mãe é relatado com mágoa por Gabriela, que se ressente por esta falta de ajuda, porém, em uma atitude ambígua, prefere a distância, pois acha que eles pouco colaborariam. Devido ao isolamento a família dispõe de uma rede de apoio pequena. Gabriela afirma que o único apoio que realmente tem é o de Deus. Tem a própria religião (espiritismo), mas passa a buscar ajuda na religião de Gilda, que é católica, participando dos rituais em nome da mãe, como se fosse para substituí-la. A forma de enfrentamento é como que ditada pela personalidade da mãe, assumida por Gabriela. Todos os eventos citados como momentos críticos vivenciados pela família são enfrentados com uma dedicação total, sem chance de recuo ou fraqueza, chegando a ponto de prejudicar a saúde daquele que assume o cuidado do parente doente. Assim se comportou Gilda na doença do esposo e da mãe, assim se comporta Gabriela no evento atual.

Para Gabriela, em especial, a ausência da mãe teve repercussões decisivas: viu-se obrigada a pedir licença de um dos empregos; teve que se desdobrar para cuidar da casa, com que não se preocupava antes e, ainda, permanecer junto da mãe todo o tempo possível permitido pelo hospital. Inicialmente sozinha, só algum tempo depois, com a chegada do irmão, pôde dividir a atenção para com Gilda. Gabriela é expansiva, relacionou-se bem com a equipe de serviço e com os outros familiares na UTI, não sufoca os sentimentos, chora e ri sem constrangimentos. Gaspar, o irmão, reagiu de forma diferente: conseguiu licença do trabalho e veio ajudar a irmã, mas ficou mais agressivo e fechado em si, ríspido na forma de falar, demonstra pouco os sentimentos e é bastante questionador em relação ao estado da mãe. Guto, o neto, nega de forma taxativa o quadro da avó, não tendo, ou não querendo ter, a clareza da gravidade do caso e do risco de morte.

\section{Estratégias de Enfrentamento}

As estratégias de enfrentamento foram classificadas segundo a 'Escala Tuolousiana de
Coping' ${ }^{12}$ e são resumidas a seguir. Nos grupos estudados observa-se a escolha de estratégias de enfrentamento, de um modo geral, de caráter positivo. A maioria alcança o objetivo do enfrentamento mais facilmente, outros têm maior dificuldade, mas todos chegam à meta desejada, no sentido de adaptação ao problema vivenciado.

Na maioria dos casos há o recurso à estratégia de focalização, que se apresenta de um modo geral de forma positiva, como uma tentativa de entender e resolver a situação que se apresenta. Já as famílias Murta e Girassol assumem uma estratégia de fuga ou negação em relação à situação, com característica essencialmente negativa, o que poderia estar relacionado ao isolamento dessas duas famílias.

A estratégia de suporte social mostra-se como um fator muito importante no enfrentamento. Esta estratégia tem como objetivo a busca de ajuda concreta nos problemas cotidianos, a busca de conselhos e informações e um apoio emocional nos momentos mais difíceis. Todas as famílias lançam mão desta estratégia, de uma forma ou de outra, procurando ajuda, umas mais, outras menos. Isso ocorre mesmo naquelas famílias que têm uma rede de apoio reduzida: ou lançam mão de um apoio antes tido como indesejado (família Murta, que se reporta à família extensa com que antes não se relacionava); ou constroem uma nova rede de amizades a partir do ocorrido (família Girassol com relação aos familiares de outros pacientes internados na UTI).

$\mathrm{Na}$ estratégia de conversão, as mudanças são configuradas para favorecer o enfrentamento, mesmo que seja em uma postura defensiva em relação ao problema. Chama-se a atenção nesta estratégia para a questão da religiosidade, que se apresenta como positiva na maioria das famílias, que utilizam a religião para tentar compreender e vivenciar melhor a situação. Na família Girassol, no entanto, a religião é utilizada para suprir a atitude de isolamento, como barganha, ou para afastar-se do problema.

A estratégia de controle, quando vivenciada pelo grupo familiar como um todo, favorece o enfrentamento, porém quando este controle se resume a apenas uma pessoa, que assume todas as responsabilidades do problema, transforma- 
se em mais uma fonte de estresse para a pessoa e, consequentemente, para todo o grupo familiar. Esta diferença pode ser vista especialmente: na família Girassol, que, com seu caráter de isolamento, abraça e controla o problema, porém sem se dar a chance para um repouso ou distração, o que se torna mais uma fonte de estresse; e na família Hortênsia, que exerce o controle da situação em uma divisão de tarefas e sentimentos, o que dilui um pouco o momento estressante.

Na percepção dos familiares, o impacto maior está nos momentos iniciais da notícia, quando o familiar ainda não teve tempo de elaborar mentalmente o evento, provocando uma reação involuntária e de auto-proteção ao estresse, que não seria caracterizada como enfrentamento. A maioria dos familiares apresentou reações iniciais que variaram entre o desespero e a inação, mesmo ao assumir imediatamente o controle da situação, tendo, como preço a pagar, o aparecimento de sintomas físicos.

No entanto, pode-se observar que todas as famílias se reorganizam diante do problema, caracterizando assim a reorganização como a primeira grande forma de enfrentamento do estresse. Estas famílias lançam mão de todos os recursos que estão ao seu alcance, ou criam novas formas, ou retomam formas antigas não mais utilizadas. Fica claro, portanto, que todos os grupos tentam alcançar a melhor adaptação possível à situação vivida, em um processo de desorganização e reorganização do microssistema familiar em função do episódio.

\section{DISCUSSÃO}

Diante destas famílias, confrontando-se com o seu sofrimento sem desviar o olhar, é possível entender o quão rica pode se tornar essa experiência que, quando olhada apenas na superfície, só se apresenta como capaz de gerar dor e desespero, individual e familiar. Neste percurso foram encontradas famílias de pessoas aparentemente frágeis e tímidas e famílias de indivíduos fortes e expansivos; famílias nucleares e com pouco suporte social e famílias extensas com uma vasta rede de amigos; enfim, pessoas que, independente dos recursos que possuíam, sempre encontraram um jeito de lidar com a situação da melhor forma que lhes era possível.

Algumas questões podem ser apontadas a partir destes resultados, tendo em vista estudos futuros.

Um primeiro aspecto de interesse é a aparente relação entre a força do impacto inicial e o papel desempenhado pelo familiar-paciente na família. No exemplo da família Begônia, o familiarpaciente, ainda muito jovem e com toda a vida pela frente, tem sua trajetória interrompida pelo evento, provocando um forte impacto. Contrapõese esta situação a um exemplo relatado pela família Girassol, no internamento em UTI de uma avó, cuja morte era esperada e vista como natural pela família por ser muito idosa, sendo a situação enfrentada com mais tranqüilidade e causando pouco impacto ao núcleo familiar. Tem-se, ainda, o caso da família Murta, onde o familiar-paciente é aquele que assume cotidianamente o papel de cuidador, ocorrendo de imediato uma paralisia da família nuclear. Nesta família a capacidade de enfrentamento é lenta e na maior parte do tempo de caráter negativo, em uma postura defensiva com relação ao evento. Já nas famílias Girassol e Hortênsia, o familiar-paciente também aparece como aquele que sempre cuidou de todos, sem tirar, no entanto, a iniciativa dos outros familiares, tornando-se o ponto de unidade para a família. Eles cuidavam e agora precisam ser cuidados, gerando uma reestruturação do núcleo familiar, que tenta se adequar ao novo momento, com o envolvimento de todos os seus membros.

Nas famílias estudadas, percebe-se, ainda, como de grande importância, o papel ocupado pela pessoa do familiar entrevistado que, na maioria dos casos, foi aquele que mais assumiu as responsabilidades durante o internamento. Este familiar pode constituir um dos nortes para a escolha das estratégias de enfrentamento por parte de toda a família, em função das estratégias adotadas por ele (ou ela).

Uma segunda questão de interesse é a relação dos familiares com a UTI. O tempo de internamento foi visto pelos familiares como uma possibilidade de tornar o ambiente da UTI mais familiar, favorecendo a confiança na equipe e no 
tratamento, como foi o caso das famílias Hortênsia e Girassol; esse fato não foi observado nos internamentos mais curtos, onde os familiares, ainda sob o impacto do ocorrido, continuaram a ver a UTI como um ambiente estranho e hostil.

Finalmente, cabe refletir sobre as lições que este estudo pode oferecer aos profissionais de saúde. Ao mergulhar nas trajetórias destas famílias, tentando manter o olhar aberto para suas nuanças, foi percebida a importância de não perder de vista, na vivência do profissional de saúde, este pequeno/grande pormenor que é o familiar diante do evento de uma internação na UTI. Este olhar deve se estender para toda a relação de assistência, seja ela na rede hospitalar ou não. A família pode se tornar um grande parceiro na assistência prestada ao individuo doente que necessite de um internamento hospitalar, ou um grande empecilho nesta assistência, se não for olhada na medida justa que lhe cabe. Uma das contribuições deste estudo está na possibilidade de oferecer aos profissionais que se deparam com um indivíduo que sofre a dor decorrente de alguma patologia a oportunidade de olhar para a família como parte integrante do processo de adoecer e do cuidar. A chave de leitura para os profissionais que lidam com a situação vivida pela família do paciente, sugerida por este trabalho, é identificar o familiar ou familiares líderes, que se apresentam como cuidadores e responsáveis naquela família, pois, a partir destes, toda a família poderá ser alcançada e ajudada a enfrentar o momento vivenciado.

A instituição hospitalar pode ter uma grande influência no momento do internamento, tanto no apresentar às famílias alternativas de enfrentamento, como no reforçar as estratégias já existentes. Este objetivo poderá ser atingido mais eficazmente se a instituição dispuser de profissionais formados especificamente para este fim, como é o caso do psicólogo hospitalar, visto ultimamente como um facilitador nas relações entre os familiares e a rede hospitalar e seus profissionais. Apesar de os profissionais que trabalham na UTI desejarem prestar assistência aos familiares, na maior parte do tempo não podem desviar o olhar do objetivo maior do seu trabalho que é o paciente. Estes profissionais de saúde necessitam, eles também, de um apoio para entender e conviver com este processo, sem desestruturar o seu próprio bem estar, tendo claro que o convívio harmonioso entre estes vários pólos só poderá gerar saldos positivos.

Espera-se que estas reflexões possam lançar uma semente para que seja repensada a forma da instituição hospitalar olhar o seu cliente, considerando todo o contexto em que esse está inserido: rede familiar, história, valores, desejos e planos, atingidos de forma muitas vezes abrupta pela doença, necessitando ser reorganizados para que o resultado seja o mais favorável possível para todos os envolvidos.

\begin{abstract}
This paper focuses on the disruptive situation provoked by the hospitalization of a member of the family due to sudden illnesses or accidents, requiring a coping reaction on the part of the family. We present results referring to six families that faced this situation, obtained through in-depth interviews with a member of the family. Firstly the families and the situations are characterized, and the coping strategies identified in each case are described. The analysis of the strategies is then presented, through the identification of differences and similarities between the cases. In every case there is the reorganization of the family in response to the event and to the resulting demands; coping strategies varied, but social support was always present. Some questions for future studies and for the preparation of health professionals are suggested.
\end{abstract}

Key words: Family and crisis. Coping strategies. Family and disease. 


\section{REFERÊNCIAS}

1. Petrini G. Notas para uma antropologia da família. In: Petrini G, Moreira LVC, Alcântara MAR, organizadores. Família XXI: entre pósmodernidade e cristianismo. São Paulo: Companhia Ilimitada; 2003. v. 1, p. 71-105.

2. Donati P. Manuale di sociologia della famiglia. $3^{\mathrm{a}}$ ed. Roma: Laterza; 2001.

3. Cowan P. Individual and family life transition. In: Cowan PA, Hetherington M, editors. Family transition. Hillsdale (NJ): Lawrence Erlbaum; 1995. p. 3-26.

4. Carter B, McGoldrick M. Mudança no ciclo de vida familiar: uma estrutura para a terapia familiar. Porto Alegre: Artes Médicas; 1995.

5. Kovacs MJ. A morte em vida. In: Bromberg MHPF, Kovacs MJ, Carvalho MMMJ, Carvalho VA. Vida e morte: laços da existência. São Paulo: Casa do Psicólogo; 1996. p. 11-33.

6. Bronfenbrenner U. A ecologia do desenvolvimento humano: experimentos naturais e planejados. Porto Alegre: Artes Médicas; 1996.

7. Alves PB. Infância, tempo e atividades cotidianas de crianças em situação de risco de rua: as contribuições da teoria dos sistemas ecológicos [tese]. Porto Alegre (RS): Universidade Federal do Rio Grande do Sul; 2002.

8. Antoniazzi AS, Dell'Aglio DD, Bandeira DR. O conceito de coping: uma revisão teórica. Estud Psicol (Natal). 1998;3(2):273-94.

9. Willner P. Animal models of stress: an overview. In: Stanford CS, Salmon P, editors. Stress: from synapse to syndrome. London: Academic Press; 1993. p. 145-65.

10. Tavares JSC. O processo de enfrentamento do câncer em famílias de mulheres com câncer de mama [tese]. Salvador (BA): Universidade Federal da Bahia; 2002.

11. McGoldrick M, Gerson R. Genogramas en la evaluación familiar. Buenos Aires: Gedisa; 1987.

12. Rafael GA. Relação de ajuda e a ação social: uma abordagem rogeriana - estudo sobre a auto-estima e as estratégias de coping realizado com estudantes da Universidade do Algarve. Lisboa: Instituto Superior de Psicologia Aplicada; 2000 [acesso em dd mmm aaaa]. Disponível em: http:// www.rogeriana.com/graça/rasocial.htm.

Recebido em 25/09/2006

Modificado em 11/10/2006 Aprovado em 17/10/2006 